\title{
Schistosomiasis appendicitis in a young Canadian immigrant
}

\author{
Angela W. Chan MD MSc, Nadia V. Giannakopoulos MD PhD, J. Damian Paton-Gay MD
}

Cite as: CMAJ 2020 August 4;192:E893. doi: 10.1503/cmaj.191565

A

27-year-old man presented to the emergency department following 4 days of worsening periumbilical pain. He had immigrated to Canada from Eritrea the previous year. $\mathrm{He}$ reported no sick contacts or recent travel history. He was afebrile with normal vital signs, experienced tenderness at McBurney's point and had a leukocyte count of 4.2 (normal 4.0-11.0) $\times 10^{9} / \mathrm{L}$ and a C-reactive protein level of 18.8 (normal $<1$ ) mg/dL. Computed tomography showed a $1.6-\mathrm{cm}$ nonperforated appendix with submucosal edema; no appendicolith was seen (image available in Appendix 1, at cmaj.ca/lookup/suppl/doi:10.1503/ cmaj.191565/-/DC1). The patient underwent laparoscopic appendectomy and was discharged home.

Histologic examination of the appendix showed an intense eosinophilic, histiocytic and lymphocytic inflammatory infiltrate in the mucosa, extending into periappendiceal fibroadipose tissues (Figure 1A). Parasitic eggs with lateral spines (Figure 1B) were present in the lamina propria and submucosa. Final pathology identified schistosoma.

Schistosomiasis accounts for $0.02 \%-6.3 \%$ cases of appendicitis worldwide; $28.6 \%$ of cases of chronic appendicitis occur in endemic regions like Africa. ${ }^{1}$ The infection is acquired through contact with freshwater snails, the parasite's intermediate host. In high-income countries, it is a rare cause of appendicitis; however, increasing international travel and immigration may alter this currently low prevalence. Schistosoma mansoni and S. haematobium, which primarily affect the gastrointestinal tract and urinary tract, respectively, account for most human infections. Microscopic detection of eggs in stool or urine is the gold standard diagnostic method. The Centers for Disease Control and Prevention recommends treatment with praziquantel at $40 \mathrm{mg} / \mathrm{kg} / \mathrm{d}$ in 2 divided doses for S. mansoni. ${ }^{2}$ There are no published guidelines about testing for schistosomiasis after appendectomy, and a 2019 systematic review identified wide heterogeneity in treatment practices for schistosomiasis in nonendemic countries. ${ }^{3}$

After discharge, we informed our patient of the diagnosis and recommended stool testing for schistosomiasis and subsequent treatment with praziquantel if he was still infected. The patient felt well, has returned to work and declined treatment.

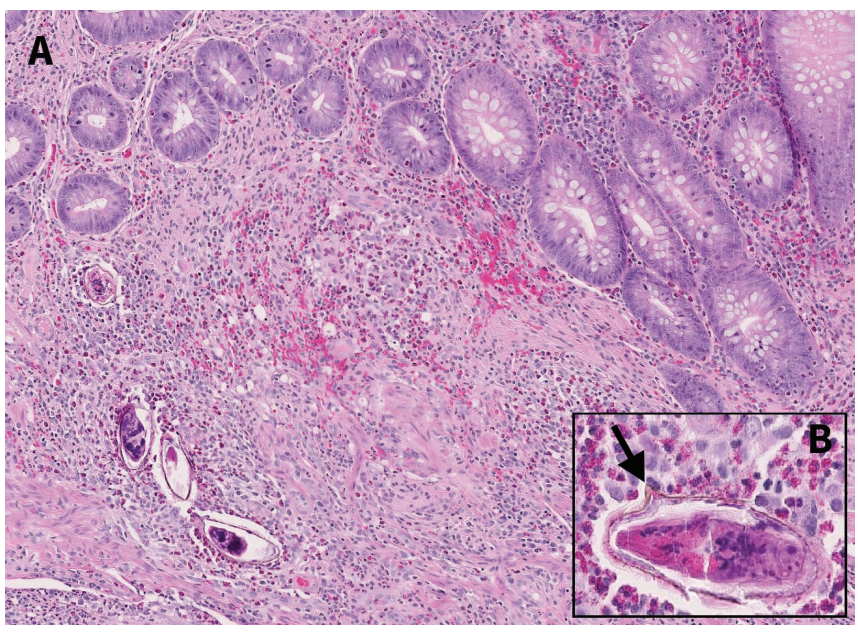

Figure 1: Appendix of a 27-year-old man: (A) appendiceal mucosa and submucosa with eosinophilic inflammatory infiltrate and multiple parasitic eggs; (B) high-power view of egg with lateral spine characteristic of Schistosoma mansoni (arrow).

\section{References}

1. López de Cenarruzabeitia I, Landolfi S, Armengol Carrasco M. Intestinal schistosomiasis as unusual aetiology for acute appendicitis, nowadays a rising disease in Western countries. Case Rep Infect Dis 2012;2012:896820.

2. Parasites: Schistosomiasis - resources for health professionals. Atlanta: Centers for Disease Control and Prevention; reviewed 2018 Apr. 11. Available: www. cdc.gov/parasites/schistosomiasis/health_professionals/index.html (accessed 2019 Dec 14).

3. Cucchetto G, Buonfrate D, Marchese V, et al. High-dose or multi-day praziquantel for imported schistosomiasis? A systematic review. J Travel Med 2019; 26:pii: taz050. doi: 10.1093/jtm/taz050.

\section{Competing interests: None declared.}

This article has been peer reviewed.

The authors have obtained patient consent.

Affiliations: Departments of Surgery (Chan, Paton-Gay) and Laboratory Medicine, and Pathology (Giannakopoulos), University of Alberta, Edmonton, Alta.

Correspondence to: Angela Chan, awc2@ualberta.ca 